\title{
Antibiotic prophylaxis for prevention of spontaneous bacterial peritonitis in liver cirrhosis: systematic review
}

\author{
R. Pimentel ${ }^{1}$, C. Gregório' ${ }^{1}$ P. Figueiredo ${ }^{1,2}$ \\ (1) Gastroenterology Department, Hospital and University Center of Coimbra, Coimbra, Portugal ; (2) Faculty of Medicine of the University of Coimbra, Coimbra, Portugal.
}

\begin{abstract}
Background and aim : Spontaneous bacterial peritonitis is a potentially life-threatening infection in patients with liver cirrhosis and ascites. Its prevention is vital to improve prognosis of cirrhotic patients. The main objective of this systematic review was to evaluate what is the most efficacious and safest antibiotic prophylactic strategy.

Methods : Studies were located by searching PubMed and Cochrane Central Register of Controlled Trials in The Cochrane Library until February 2019. Randomized controlled trials evaluating primary or secondary spontaneous bacterial peritonitis prophylaxis in cirrhotic patients with ascites were included. The selection of studies was performed in two stages: screening of titles and abstracts, and assessment of the full papers identified as relevant, considering the inclusion criteria. Data were extracted in a standardized way and synthesized qualitatively.

Results : Fourteen studies were included. This systematic review demonstrated that daily norfloxacin is effective as a prophylactic antibiotic for the prevention of spontaneous bacterial peritonitis in patients with cirrhosis. Once weekly ciprofloxacin was not inferior to once daily norfloxacin, with good tolerance and no induced resistance. Trimethoprim-sulfamethoxazole and norfloxacin have similar efficacy for primary and secondary prophylaxis of spontaneous bacterial peritonitis, however, trimethoprim-sulfamethoxazole was associated with an increased risk of developing an adverse event. Rifaximin was more effective than norfloxacin in the secondary prophylaxis of spontaneous bacterial peritonitis, with a significant decrease in adverse events and mortality rate.

Conclusions : Continuous long-term selective intestinal decontamination with norfloxacin is the most widely used prophylactic strategy in spontaneous bacterial peritonitis, yet other equally effective and safe options are available. (Acta gastroenterol. belg., 2021, 84, 333-341)
\end{abstract}

Keywords : antibiotics, ascites, liver cirrhosis, peritonitis, prophylaxis.

\section{Introduction}

Bacterial infections constitute a major complication of liver cirrhosis (1). Spontaneous bacterial peritonitis (SBP) is a frequent and potentially life-threatening bacterial infection in patients with liver cirrhosis and ascites (2). Modifications in intestinal microbiota, altered intestinal permeability, bacterial translocation and systemic immune dysfunction constitute the cornerstones for the development of SBP in cirrhotic patients. These events facilitate bacterial translocation from intestinal lumen to mesenteric lymph nodes, and subsequently to portal and systemic circulation, from where ascitic fluid could be colonized and, under appropriate conditions, infection could develop (1). These concepts explain why gram-negative bacteria, particularly Enterobacteriaceae, were considered the major causative microorganisms of
SBP. However, over the last decade, a shift in microbial patterns of SBP towards an increasing incidence of grampositive bacteria and an increasing resistance rate to first line antibiotics have been reported (3).

The diagnosis of SBP is made according to international guidelines (4) in patients with liver cirrhosis if the ascites polymorphonuclear cell count exceeds 250 cells $/ \mu \mathrm{L}$, in the absence of an intra-abdominal source of infection, with or without growth of bacteria in the ascitic fluid (2).

Cirrhotic patients with low total protein content in ascitic fluid, prior episodes of SBP and advanced liver disease, are at high risk for SBP (5).

The incidence of SBP reaches $3.5 \%$ at one year in outpatients with decompensated cirrhosis and varies between $7 \%$ and $30 \%$ in hospitalized patients with cirrhosis and ascites (1).

Spontaneous bacterial peritonitis is associated with poor prognosis. After an episode of SBP, probability of survival at one year is $30-50 \%$ and $25-30 \%$ at two years (4). In the survivors, the 1-year probability rate of SBP recurrence is approximately $70 \%$ if no prophylaxis is indicated $(1,4)$.

Consequently, prevention of SBP is one of the vital strategies to improve prognosis of cirrhotic patients (6). Discussion regarding the use of antibiotherapy to prevent SBP is old, however considerable debate still exists on the optimal prophylactic antibiotic strategy.

The main objectives of this systematic review were to assess clinical efficacy of primary and secondary prophylaxis of SBP and to evaluate what is the most efficacious and safest antibiotic prophylactic strategy.

\section{Methods}

The protocol was developed following international guidelines for systematic reviews (7) to answer the question: what is the evidence regarding the antibiotic prophylaxis of SBP.

Correspondence to : Raquel Alexandra Gomes dos Reis Pimentel; Praceta Prof. Mota Pinto CHUC, 3000-075 Coimbra, Portugal.

Email : raquelreispimentel@hotmail.com

Submission date : 10/10/2020 Acceptance date : $28 / 12 / 2020$ 


\section{Search strategy and study selection}

Studies were located by searching electronic databases (PubMed and Cochrane Central Register of Controlled Trials (CENTRAL) in The Cochrane Library) until February 2019. The search strategy used four keywords (MeSH terms): liver cirrhosis, peritonitis, prophylaxis and antibiotics. In addition to searching electronic databases, bibliographies of all potentially relevant studies and international guidelines were searched by hand.

Inclusion criteria used to select studies for this systematic review were: (i) population: studies of adult participants ( $>18$ years old) diagnosed with liver cirrhosis (regardless of etiology and severity) and ascites, under primary or secondary SBP prophylaxis; (ii) intervention: primary or secondary SBP prophylaxis; (iii) comparative intervention: placebo, other antibiotics or no prophylaxis; (iv) outcomes: clinical efficacy of antibiotic prophylaxis (measured by incidence of SBP, incidence of infections other than SBP and/or overall infection rate), adverse events, mortality rate and microbiological profile; (v) study design: randomized controlled trials (RCT) and controlled trials (CT). Only studies written in English were included.

Studies selection was performed in two stages. The first stage was a screening of titles and abstracts against the inclusion criteria to identify potentially relevant articles. When a definite decision based on title or abstract was not possible, the full papers were assessed. Rejected studies were grouped in those that did not meet the review objectives and those that addressed the topic of interest but failed on one or more criteria (population, intervention, comparative intervention, outcomes and/ or study design). When the abstract was not available, the studies were also excluded. The second stage was the assessment of the full papers identified as relevant at the initial screening. If full papers were not accessible, the studies were excluded.

\section{Data extraction and quality assessment}

Data extraction was performed by one reviewer. Data extraction forms were standardized and decision rules about coding data were used. Only essential information for descriptive purposes of the systematic review were included in data extraction forms, namely: first author; publication year; study design; subjects characteristics (age, disease and co-morbidities) and number of subjects allocated to intervention and control groups; intervention description (type of antibiotic and respective dosage) and control group; treatment duration; outcome measures; and key results of the study analysis.

The Cochrane Collaboration's recommended tool for assessing risk of bias (7) was the quality assessment process used in this review, in which critical judgment was made independently for the most important domains (random sequence generation, allocation concealment, blinding of participants and personnel and completeness of outcome data). The process was a blind assessment (to the names of the authors, institutions, journals and results of the study).

\section{Data synthesis and analysis}

Trials were stratified according to the type of prophylaxis: primary prophylaxis studies, secondary prophylaxis studies, and mixed population studies including both participants under primary and secondary prophylaxis. Data were synthesized qualitatively.

Clinical efficacy was evaluated by means of the following outcomes: incidence of SBP, incidence of infections other than SBP and/or overall infection rate.

Regarding safety, adverse reactions were analyzed and compared between groups concerning severity, requirement of symptomatic treatment, dose adjustments or withdrawals from the study.

Treatment efficacy was established by statistical significance ( $p$-value) knowing that values of $p<0.05$ were considered statistically significant, and/or by $95 \%$ confidence intervals which point to a clinically relevant difference when the zero value is not included in the $95 \%$ confidence limits.

\section{Results}

\section{Study identification and selection}

A preliminary search in electronic databases (PubMed and Cochrane) identified a total of 60 potentially relevant articles. All of these articles were submitted to an initial screening of titles and abstracts against inclusion criteria, resulting in exclusion of 43 studies: 16 were repeated articles; 20 did not meet the review objectives and six failed on one or more inclusion criteria. One study was also excluded, because abstract was not available.

A definite decision based on title or abstract was not possible in three cases, hence the full papers were obtained for detailed assessment aiming to evaluate if the inclusion criteria were or not satisfied. In addition to these, another 14 potentially relevant articles (not excluded based on title and abstract) were assessed for eligibility. In total, 17 full-text articles were retrieved and assessed for eligibility. Of them, two were excluded: one did not address the predefined outcomes and one was not accessible.

The remaining 15 publications met all inclusion criteria. However, two of them were excluded: one because it was not a RCT, but a prospective longitudinal observational study, and the other one because its results were not explicit in relation to the clinical efficacy of SBP prophylaxis.

Finally, one study was included based on a manual review of all potentially relevant studies and international guidelines.

At the end, 14 studies were included in the systematic review. The flowchart of studies selection is shown in Fig. 1. 


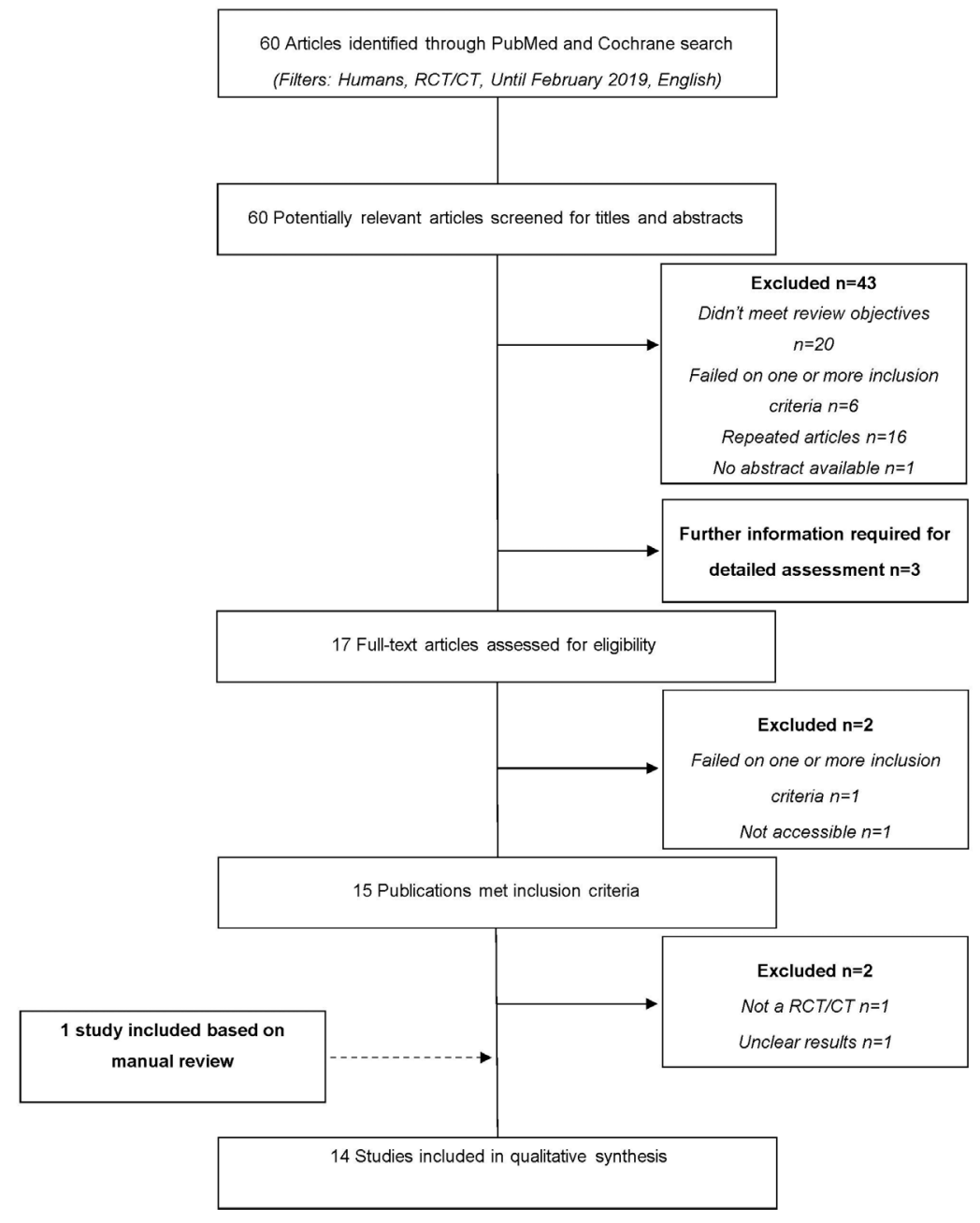

Figure 1. - Flowchart of studies identification and selection process. RCT/CT, randomized controlled trial/controlled trial.

\section{Risk of bias assessment}

The method used to generate random sequence and to conceal allocation sequence was adequately performed in seven studies $(5,6,8,9,10,11,12)$ ("low risk" of selection bias). Two studies $(13,14)$ were classified as "high risk" due to inadequate generation of a randomized sequence. In the remaining five studies $(15,16,17,18,19)$ the methods were poorly reported making it difficult to evaluate the risk of selection bias ("unclear risk").

Blinding of participants and investigators was clearly stated and not broken in four studies $(11,12,13,14)$ ("low

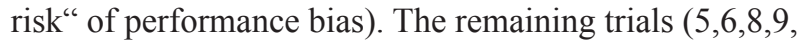
$10,15,16,17,18,19$ ) were not double-blinded ("high risk").

In the majority of studies $(5,6,8,9,10,11,12,13,14,16$, 17) missing data was imputed using appropriate methods such as intention-to-treat (ITT) analysis or, if an ITT analysis was not performed, the numbers and reasons for withdrawals or exclusions from the study were reported ("low risk" of attrition bias). Only three studies $(15,18,19)$ were considered with "high risk" of attrition bias.

\section{Outcomes summary}

Primary prophylaxis

In a randomized and controlled trial, Assem et al. (10) compared the efficacy and safety of alternating use of rifaximin and norfloxacin (rifaximin $1100 \mathrm{mg}$ daily, for one month, alternating with norfloxacin $400 \mathrm{mg}$ daily, for another month) with norfloxacin or rifaximin alone as primary prophylaxis in patients with high risk of developing SBP and hepatorenal syndrome (HRS) (Table 1). Two hundred and thirty-nine patients were included (79 in the combined regimen group, 78 in the norfloxacin group and 82 in the rifaximin group) and followed-up over a 6-month period. Alternating use of norfloxacin and rifaximin showed a higher prophylactic rate in comparison with the other regimens, with a prevention rate of $74.7 \%$ (versus $56.4 \%$ for norfloxacin and $68.3 \%$ for rifaximin), with statistically significant difference between combined regimen group and norfloxacin group $(\mathrm{p}=0.016)$. There was no statistical significant difference between norfloxacin versus rifaximin alone neither 
Table 1. - Primary prophylaxis studies

\begin{tabular}{|c|c|c|c|c|c|c|c|}
\hline Study & Design & Risk of bias & Risk factors for SBP & Study arms (N) & $\begin{array}{l}\text { Follow- } \\
\text { up }\end{array}$ & SBP & p-value \\
\hline $\begin{array}{l}\text { Assem et al. (10) } \\
(2016)\end{array}$ & $\mathrm{RCT}$ & $\begin{array}{l}\text { "Low" SB } \\
\text { "High" PB } \\
\text { "Low" AB }\end{array}$ & $\begin{array}{c}\mathrm{TP}<1.5 \mathrm{~g} / \mathrm{dL} \\
\mathrm{CP} \geq 9 \mathrm{pts}+\mathrm{BRB} \geq 3 \mathrm{mg} / \mathrm{dL} \\
\text { Renal dysfunction }\end{array}$ & $\begin{array}{c}\text { Rifaximin } 1100 \mathrm{mg} / \text { day, } 1 \mathrm{mo}- \\
\text { Norfloxacin } 400 \mathrm{mg} / \text { day, } 1 \mathrm{mo} \\
\qquad(\mathrm{N}=79) \\
\text { Vs. } \\
\text { Norfloxacin } 400 \mathrm{mg} / \text { day }(\mathrm{N}=78) \\
\text { Vs. } \\
\text { Rifaximin } 1100 \mathrm{mg} / \text { day }(\mathrm{N}=82)\end{array}$ & $6 \mathrm{mo}$ & $\begin{array}{l}25.3 \% \\
\text { Vs. } \\
43.6 \% \\
\text { Vs. } \\
31.7 \%\end{array}$ & $\begin{array}{l}* \mathrm{p}=0.016 \\
* * \mathrm{p}>0.05\end{array}$ \\
\hline $\begin{array}{l}\text { Fernández et al. (11) } \\
\text { (2007) }\end{array}$ & $\begin{array}{l}\mathrm{RCT} \\
\mathrm{DB}\end{array}$ & $\begin{array}{l}\text { "Low" SB } \\
\text { "Low" PB } \\
\text { "Low" AB }\end{array}$ & $\begin{array}{c}\mathrm{TP}<1.5 \mathrm{~g} / \mathrm{dL} \\
\mathrm{CP}>9 \mathrm{pts}+\mathrm{BRB}>3 \mathrm{mg} / \mathrm{dL} \\
\text { Renal dysfunction }\end{array}$ & $\begin{array}{c}\text { Norfloxacin } 400 \mathrm{mg} / \text { day }(\mathrm{N}=35) \\
\text { Vs. } \\
\text { Placebo }(\mathrm{N}=33)\end{array}$ & $1 \mathrm{yr}$ & $\begin{array}{l}6 \% \\
\text { Vs. } \\
30 \% \\
\end{array}$ & $\mathrm{p}=0.02$ \\
\hline $\begin{array}{l}\text { Grangé et al. (12) } \\
\text { (1998) }\end{array}$ & $\begin{array}{l}\text { RCT, } \\
\text { DB }\end{array}$ & $\begin{array}{l}\text { "Low" SB } \\
\text { "Low" PB } \\
\text { "Low" AB }\end{array}$ & $\mathrm{TP}<1.5 \mathrm{~g} / \mathrm{dL}$ & $\begin{array}{c}\text { Norfloxacin } 400 \mathrm{mg} / \text { day }(\mathrm{N}=53) \\
\text { Vs. } \\
\text { Placebo }(\mathrm{N}=54)\end{array}$ & $6 \mathrm{mo}$ & $\begin{array}{l}\dagger 1.9 \% \\
\text { Vs. } \\
\dagger 16.7 \%\end{array}$ & $\mathrm{p}<0.03$ \\
\hline $\begin{array}{l}\text { Novella et al. (17) } \\
\text { (1997) }\end{array}$ & $\mathrm{RCT}$ & $\begin{array}{l}\text { "Unclear” SB } \\
\text { "High" PB } \\
\text { "Low" AB }\end{array}$ & $\begin{array}{c}\mathrm{TP} \leq 1 \mathrm{~g} / \mathrm{dL} \\
\mathrm{BRB}>2.5 \mathrm{mg} / \mathrm{dL}\end{array}$ & $\begin{array}{c}\text { Norfloxacin } 400 \mathrm{mg} / \text { day, } \\
\text { continuously }(\mathrm{N}=56) \\
\text { Vs. } \\
\text { Norfloxacin } 400 \mathrm{mg} / \text { day, } \\
\text { hospitalization }(\mathrm{N}=53)\end{array}$ & $\begin{array}{l}43 \pm \\
3 \mathrm{w} \mathrm{k}\end{array}$ & $\begin{array}{l}1.78 \% \\
\text { Vs. } \\
16.9 \%\end{array}$ & $\mathrm{p}<0.01$ \\
\hline
\end{tabular}

SBP, spontaneous bacterial peritonitis ; N, number of participants ; RCT, randomized controlled trial ; DB, double-blind ; SB, selection bias ; PB, performance bias ; AB, attrition bias ; TP, total protein in ascitic fluid ; CP, Child-Pugh score ; pts, points ; BRB, serum bilirubin level ; wk, week ; mo, months; yr, year. $\uparrow \%$ of severe infections, including SBP. *p-value between combined regimen and norfloxacin. **p-value between combined regimen and rifaximin and between norfloxacin and rifaximin.

between rifaximin versus alternating use of norfloxacin and rifaximin $(p>0.05)$. There was no significant difference among the study groups with respect to the incidence or severity of adverse events and no patient withdrew from the study because of an adverse event.

In a randomized, double-blind, placebo-controlled trial, Fernández et al. (11) evaluated the efficacy and safety of primary prophylaxis with norfloxacin in patients at high risk of developing SBP and HRS, over 1 yearperiod (Table 1). Thirty-five patients received norfloxacin $400 \mathrm{mg}$ /day and 33 placebo. Fourteen patients (40\%) in the norfloxacin group developed infections and 19 (58\%) in the placebo group, with no statistically significant difference between groups. Two patients $(6 \%)$ in the norfloxacin group and $10(30 \%)$ in the placebo group developed SBP, with statistically significant difference $(p=0.02)$. The 1-year probability of developing SBP was significantly lower in the norfloxacin group $(\mathrm{p}=0.007)$. Mortality within the first three months of follow-up was significantly higher in the placebo group (10 versus two patients; $p=0.02$ ). The 1 -year probability of survival was significantly higher in patients receiving norfloxacin ( $60 \%$ versus $48 \%$ in the placebo group; $p=0.05$ ). No side effects related to norfloxacin or placebo were observed. Eleven of 13 gram-negative bacilli isolated in the norfloxacin group were resistant to quinolones compared with only one of six isolated in the placebo group $(\mathrm{p}<0.01)$, however no cases of SBP caused by quinolone resistant bacteria were detected in this study.

In a randomized, double-blind, placebo-controlled study, Grangé et al. (12) evaluated the efficacy and safety of norfloxacin for primary prophylaxis of gram-negative bacilli infections in cirrhotic patients (Table 1). One hundred and seven patients were randomly allocated to receive oral norfloxacin $400 \mathrm{mg} /$ day $(\mathrm{n}=53)$ or placebo $(\mathrm{n}=54)$, over a 6-month period. A total of 13 infections $(24.1 \%)$ was observed in the placebo group versus seven $(13 \%)$ in the norfloxacin group, with no statistical significant difference between groups. Severe infections (SBP, neutrocytic ascites and bacteremia) developed in nine patients in the placebo group and in one patient in the norfloxacin group $(\mathrm{p}<0.03)$. The probability of gram-negative infection was significantly lower among patients treated with norfloxacin than among those treated with placebo $(p<0.0177)$. Side effects requiring the withdrawal of treatment occurred in two patients in the norfloxacin group (nausea, hypersomnia). Although there was no between-group difference in overall mortality rate $(15 \%$ in the norfloxacin group versus $18 \%$ in the placebo group), four deaths observed in the placebo group were directly linked to infection, whereas there were no infection-related deaths in the norfloxacin group.

In a multicenter, randomized and controlled trial, Novella et al. (17) assessed the efficacy of continuous long-term use of norfloxacin in the prevention of the first episode of SBP in cirrhotic patients at high risk (Table 1). One hundred and nine patients were enrolled to receive norfloxacin $400 \mathrm{mg}$ daily continuously (group 1, n=56) or norfloxacin $400 \mathrm{mg}$ daily only during hospitalization (group 2, $\mathrm{n}=53$ ). The overall incidence of infections during the study period was $25 \%$ in group 1 and $33.9 \%$ in group 2, with no statistical significant difference between study groups. There was only one episode of SBP in group $1(1.78 \%)$, whereas there were nine in group $2(16.9 \%)$ $(p<0.01)$. The incidence of extraperitoneal infections was similar in both groups (25\% in group 1 and $24.5 \%$ in group 2). Resistance to norfloxacin was observed in $90 \%$ (nine of 10) of Escherichia coli isolated in infections from group 1 and in $36.3 \%$ (four of 11) from group 2, 
Table 2. - Secondary prophylaxis studies

\begin{tabular}{|c|c|c|c|c|c|c|c|}
\hline Study & Design & Risk of bias & Risk factors for SBP & Study arms (N) & $\begin{array}{c}\text { Follow- } \\
\text { up }\end{array}$ & SBP & p-value \\
\hline $\begin{array}{l}\text { Elfert et al. (8) } \\
(2016)\end{array}$ & $\mathrm{RCT}$ & $\begin{array}{l}\text { "Low" SB } \\
\text { "High" PB } \\
\text { "Low" AB }\end{array}$ & Previous episode of SBP & $\begin{array}{c}\text { Rifaximin } 1200 \mathrm{mg} / \text { day }(\mathrm{N}=103) \\
\text { Vs. } \\
\text { Norfloxacin } 400 \mathrm{mg} / \text { day }(\mathrm{N}=92)\end{array}$ & $6 \mathrm{mo}$ & $\begin{array}{l}3.88 \% \\
\text { Vs. } \\
14.13 \%\end{array}$ & $\mathrm{p}=0.04$ \\
\hline $\begin{array}{l}\text { Mostafa et al. (15) } \\
\text { (2015) }\end{array}$ & RCT & $\begin{array}{l}\text { "Unclear" SB } \\
\text { "High” PB } \\
\text { "High" AB }\end{array}$ & Previous episode of SBP & $\begin{array}{l}\text { Rifaximin } 800 \mathrm{mg} / \text { day }(\mathrm{N}=40) \\
\text { Vs. } \\
\text { Norfloxacin } 400 \mathrm{mg} / \text { day }(\mathrm{N}=30)\end{array}$ & $6 \mathrm{mo}$ & $\begin{array}{c}0 \% \\
\text { Vs. } \\
16.6 \%\end{array}$ & NAD \\
\hline $\begin{array}{l}\text { Bauer et al. (9) } \\
(2002)\end{array}$ & $\mathrm{RCT}$ & $\begin{array}{l}\text { "Low" SB } \\
\text { "High" PB } \\
\text { "Low" AB }\end{array}$ & Previous episode of SBP & $\begin{array}{l}\text { Rufloxacin } 400 \text { mg/wk (N=39) } \\
\text { Vs. } \\
\text { Norfloxacin } 400 \text { mg/day }(\mathrm{N}=40)\end{array}$ & $1 \mathrm{yr}$ & $\begin{array}{l}31 \% \\
\text { Vs. } \\
15 \%\end{array}$ & $\mathrm{p}=0.09$ \\
\hline $\begin{array}{l}\text { Ginés et al. (14) } \\
\text { (1990) }\end{array}$ & $\mathrm{CT}, \mathrm{DB}$ & $\begin{array}{l}\text { "High" SB } \\
\text { "Low" PB } \\
\text { "Low" AB }\end{array}$ & Previous episode of SBP & $\begin{array}{c}\text { Norfloxacin } 400 \mathrm{mg} / \text { day }(\mathrm{N}=40) \\
\text { Vs. } \\
\text { Placebo }(\mathrm{N}=40)\end{array}$ & $1 \mathrm{yr}$ & $\begin{array}{l}12 \% \\
\text { Vs. } \\
35 \%\end{array}$ & $\mathrm{p}=0.014$ \\
\hline
\end{tabular}

SBP, spontaneous bacterial peritonitis ; N, number of participants ; RCT, randomized controlled trial ; CT, controlled trial ; DB, double-blind ; SB, selection bias ; PB, performance bias ; AB, attrition bias ; wk, week ; mo, months ; yr, year ; NAD, No available data.

with statistically significant difference between groups $(\mathrm{p}<0.05)$. The overall incidence of infections caused by norfloxacin-resistant bacteria was higher in patients receiving continuous long-term norfloxacin $(19.6 \%$ in group 1 versus $15 \%$ in group 2), although this difference was not statistically significant. The authors reported low rates of side effects attributable to norfloxacin because only one patient receiving long-term norfloxacin developed oral candidiasis. Mortality rate was similar between groups $(23.2 \%$ in group 1 and $30.2 \%$ in group 2), without statistical significant difference.

\section{Secondary prophylaxis}

In a randomized, controlled, open-label parallel-group trial, Elfert et al. (8) compared the safety and efficacy of rifaximin versus norfloxacin for the secondary prevention of SBP (Table 2). Two hundred and sixty-two patients were randomized to receive $400 \mathrm{mg}$ of norfloxacin daily or $1200 \mathrm{mg}$ of rifaximin daily, for six months. Four patients out of $103(3.88 \%)$ on rifaximin and 13 patients out of 92 $(14.13 \%)$ on norfloxacin developed SBP. The difference was statistically significant $(\mathrm{p}=0.04)$. All positive cultures of ascitic fluid from patients who developed new SBP episodes were resistant to norfloxacin. There was a significant decrease in side effects in the rifaximin group $(p=0.033)$. No serious adverse events were reported. The mortality rate was significantly decreased in the rifaximin group compared with the norfloxacin group (13.74\% versus $24.43 \%, \mathrm{p}=0.044$ ), with a significant decrease in encephalopathy-related deaths in the rifaximin group.

In a prospective, randomized and controlled study, Mostafa et al. (15) evaluated the efficacy of rifaximin in the secondary prophylaxis of SBP (Table 2). Seventy patients were enrolled in the study and divided into two groups: group $1(\mathrm{n}=40)$ received a daily oral dose of 800 $\mathrm{mg}$ rifaximin and group $2(\mathrm{n}=30)$ received a daily oral dose of $400 \mathrm{mg}$ norfloxacin, for six months. The use of rifaximin resulted in a reduction of SBP episodes, with any case on rifaximin therapy compared with five cases on norfloxacin therapy $(16.6 \%)$. There were only minor adverse effects reported with patients on norfloxacin, all of them symptomatically treated. On the other hand, any adverse effects were reported in the rifaximin group.

Bauer et al. (9) compared the efficacy of rufloxacin $400 \mathrm{mg}$ once a week with norfloxacin $400 \mathrm{mg}$ once a day, in the prevention of SBP recurrence in cirrhotic patients with ascites (Table 2). Seventy-nine patients were enrolled and assigned to receive either norfloxacin $(n=40)$ or rufloxacin $(n=39)$, over 1 year-period. SBP recurred in six patients $(15 \%)$ from norfloxacin group and in 12 patients $(31 \%)$ from rufloxacin group, with no significant difference between groups $(\mathrm{p}=0.09)$. The 1-year probability of SBP recurrence did not differ significantly between norfloxacin and rufloxacin ( $26 \%$ versus $36 \%$, respectively; $p=0.16$ ). However, the three-month probability of SBP recurrence differed significantly ( $3 \%$ versus $19 \%$ in norfloxacin and rufloxacin groups, respectively ; $\mathrm{p}=0.03$ ). Two of seven episodes of SBP with Enterobacteriaceae in this study were caused by quinolone-resistant strains. Infections other than SBP occurred in seven patients (17\%) from norfloxacin group and six patients $(15 \%)$ from rufloxacin group, with no statistical significant difference $(p=0.96)$. Drug administration was stopped because of side effects in three patients from norfloxacin group (severe diarrhea, granulocytopenia, urticaria) and three patients from rufloxacin group (nausea, vomiting, headache). All side effects disappeared on discontinuation of the drugs.

In a double-blind, placebo-controlled trial conducted by Ginés et al. (14), 80 patients with cirrhosis and a previous episode of SBP were included and followedup over a year to assess whether the long-term administration of norfloxacin $400 \mathrm{mg}$ /day prevents SBP recurrence (Table 2). Fourteen patients (35\%) from the placebo group and five (12\%) from the norfloxacin group experienced an episode of SBP during follow-up $(\mathrm{p}=0.014)$. The 1-year probability of SBP recurrence was $20 \%$ in the norfloxacin group and $68 \%$ in the placebo group ( $\mathrm{p}=0.0063$ ). Infections other than SBP developed 
Table 3. - Mixed populations studies

\begin{tabular}{|c|c|c|c|c|c|c|c|}
\hline Study & Design & Risk of bias & Risk factors for SBP & Study arms (N) & Follow-up & SBP & p-value \\
\hline $\begin{array}{l}\text { Yim et al. (6) } \\
\text { (2018) }\end{array}$ & RCT & $\begin{array}{l}\text { "Low" SB } \\
\text { "High" PB } \\
\text { "Low" AB }\end{array}$ & $\begin{array}{c}\text { Previous episode of SBP } \\
\mathrm{TP} \leq 1.5 \mathrm{~g} / \mathrm{dL}\end{array}$ & $\begin{array}{c}\text { Norfloxacin } 400 \mathrm{mg} / \text { day }(\mathrm{N}=62) \\
\text { Vs. } \\
\text { Ciprofloxacin } 750 \mathrm{mg} / \mathrm{wk}(\mathrm{N}=62)\end{array}$ & $1 \mathrm{yr}$ & $\begin{array}{c}7.3 \% \\
\text { Vs. } \\
5.3 \%\end{array}$ & $\mathrm{p}=0.712$ \\
\hline $\begin{array}{l}\text { Lontos et al. (5) } \\
(2014)\end{array}$ & RCT & $\begin{array}{l}\text { "Low" SB } \\
\text { "High" PB } \\
\text { "Low" AB }\end{array}$ & $\begin{array}{c}\text { Previous episode of SBP } \\
\text { TP }<1,5 \mathrm{~g} / \mathrm{dL} \\
\text { BRB }>43 \mu \mathrm{mol} / \mathrm{L}\end{array}$ & $\begin{array}{c}\text { Norfloxacin } 400 \mathrm{mg} / \text { day }(\mathrm{N}=40) \\
\text { Vs. } \\
\text { Trimethoprim-sulfamethoxazole } \\
160 \mathrm{mg}-800 \mathrm{mg} / \text { day }(\mathrm{N}=40)\end{array}$ & $1 \mathrm{yr}$ & $\begin{array}{l}5 \% \\
\text { Vs. } \\
5 \%\end{array}$ & $\mathrm{p}=0.60$ \\
\hline $\begin{array}{l}\text { Alvarez et al. (16) } \\
(2005)\end{array}$ & RCT & $\begin{array}{l}\text { "Unclear" SB } \\
\text { "High" PB } \\
\text { "Low" AB }\end{array}$ & $\begin{array}{c}\text { Previous episode of SBP } \\
\mathrm{TP} \leq 1 \mathrm{~g} / \mathrm{dL} \\
\mathrm{BRB} \geq 2.5 \mathrm{mg} / \mathrm{dL}\end{array}$ & $\begin{array}{l}\text { Norfloxacin } 400 \mathrm{mg} / \text { day }(\mathrm{N}=32) \\
\text { Vs. } \\
\text { Trimethoprim-sulfamethoxazole } \\
160-800 \mathrm{mg} / 5 \text { days a wk }(\mathrm{N}=25)\end{array}$ & $\begin{array}{l}163 \text { days } \\
\text { Vs. } \\
182 \text { days }\end{array}$ & $\begin{array}{c}9.4 \% \\
\text { Vs. } \\
16 \%\end{array}$ & $\mathrm{p}=0.68$ \\
\hline $\begin{array}{l}\text { Rolachon et al. (13) } \\
\text { (1995) }\end{array}$ & RCT, DB & $\begin{array}{l}\text { "High" SB } \\
\text { "Low" PB } \\
\text { "Low" AB }\end{array}$ & $\begin{array}{c}\text { Previous episode of SBP } \\
\text { TP } \leq 1,5 \mathrm{~g} / \mathrm{dl}\end{array}$ & $\begin{array}{c}\text { Ciprofloxacin } 750 \mathrm{mg} / \mathrm{wk}(\mathrm{N}=28) \\
\text { Vs. } \\
\text { Placebo }(\mathrm{N}=32)\end{array}$ & $6 \mathrm{mo}$ & $\begin{array}{l}3.6 \% \\
\text { Vs. } \\
22 \%\end{array}$ & $\mathrm{p}<0.05$ \\
\hline $\begin{array}{l}\text { Singh et al. (18) } \\
\text { (1995) }\end{array}$ & RCT & $\begin{array}{l}\text { "Unclear" SB } \\
\text { "High" PB } \\
\text { "High" AB }\end{array}$ & $\begin{array}{c}\text { Previous episode of SBP } \\
\mathrm{TP}<1 \mathrm{~g} / \mathrm{dL} \\
\mathrm{BRB}>3 \mathrm{mg} / \mathrm{dL} \\
\text { Renal dysfunction }\end{array}$ & $\begin{array}{c}\text { Trimethoprim-sulfamethoxazole/5 } \\
\text { days a wk }(\mathrm{N}=30) \\
\text { Vs. } \\
\text { No prophylaxis }(\mathrm{N}=30)\end{array}$ & 90 days & $\begin{array}{l}\dagger 3 \% \\
\text { Vs. } \\
\dagger 27 \%\end{array}$ & $\mathrm{p}=0.025$ \\
\hline $\begin{array}{l}\text { Soriano et al. (19) } \\
\text { (1991) }\end{array}$ & RCT & $\begin{array}{l}\text { "Unclear" SB } \\
\text { "High" PB } \\
\text { "High" AB }\end{array}$ & $\begin{array}{c}\text { Previous episode of SBP } \\
\text { TP }<1.5 \mathrm{~g} / \mathrm{dL}\end{array}$ & $\begin{array}{c}\text { Norfloxacin } 400 \mathrm{mg} / \text { day }(\mathrm{N}=32) \\
\text { Vs. } \\
\text { No prophylaxis }(\mathrm{N}=31)\end{array}$ & $\begin{array}{c}26.75 \pm \\
14.87 \text { days } \\
\text { Vs. } \\
23.68 \pm \\
13.43 \text { days }\end{array}$ & $\begin{array}{c}0 \% \\
\text { Vs. } \\
22.5 \%\end{array}$ & $\mathrm{p}<0.05$ \\
\hline
\end{tabular}

SBP, spontaneous bacterial peritonitis ; N, number of participants ; RCT, randomized controlled trial ; DB, double-blind ; SB, selection bias ; PB, performance bias ; AB, attrition bias ; TP, total protein in ascitic fluid ; BRB, serum bilirubin level ; wk, week ; mo, months ; yr, year. †\% of spontaneous bacterial peritonitis or spontaneous bacteremia.

in three patients $(7.5 \%)$ from the norfloxacin group and five (12\%) from the placebo group, with no significant difference. Side effects related to norfloxacin occurred in only one patient (oral and esophageal candidiasis, resolved with oral nystatin treatment). Seven patients from the norfloxacin group and 10 from the placebo group died during follow-up.

\section{Mixed population}

In a prospective, multicenter, open-label, randomized and controlled trial, Yim et al. (6) compared daily norfloxacin and weekly ciprofloxacin for the prevention of SBP (Table 3). Cirrhotic patients were randomly assigned into norfloxacin $400 \mathrm{mg}$ once daily $(\mathrm{n}=62)$ or ciprofloxacin $750 \mathrm{mg}$ once weekly ( $\mathrm{n}=62$ ), and followedup for 12 months. Seven patients in the norfloxacin group and five in the ciprofloxacin group were lost to follow-up. During the study period, SBP developed in four patients $(7.3 \%)$ in the norfloxacin group and in three patients $(5.3 \%)$ in the ciprofloxacin group, without statistically significant difference $(\mathrm{p}=0.712)$. A pathogenic organism (Escherichia coli) was isolated in only one patient, who received ciprofloxacin, and it was resistant to quinolone. In a subgroup analysis of patients who did not have a history of SBP (primary prophylaxis), including 56 patients in the norfloxacin group and 52 patients in the ciprofloxacin group, the incidence of SBP was not different between the groups $(2.0 \%$ versus $4.2 \%$, respectively, $\mathrm{p}=0.613$ ). The authors concluded that once weekly administration of ciprofloxacin was not inferior to once daily norfloxacin.
Lontos et al. (5) compared the efficacy of norfloxacin and trimethoprim-sulfamethoxazole in the prophylaxis of SBP (Table 3). Eighty cirrhotic patients with ascites at high risk for SBP were randomized to receive either norfloxacin $400 \mathrm{mg}$ daily $(\mathrm{n}=40)$ or trimethoprimsulfamethoxazole $160 \mathrm{mg} / 800 \mathrm{mg}$ daily $(\mathrm{n}=40)$, over a year. Nineteen $(23.8 \%)$ episodes of infections occurred during the study period. The overall incidence of SBP was low $(5 \%)$. No statistically significant differences were noted in the incidence of infections overall, SBP or bacteremia between the norfloxacin and trimethoprimsulfamethoxazole groups. In this trial, $37.5 \%$ of isolated organisms were quinolone-resistant while $50 \%$ were resistant to trimethoprim-sulfamethoxazole. Although there was no statistical significant difference between groups in relation to adverse events (seven (17.5\%) for norfloxacin group versus nine $(25 \%)$ for trimethoprimsulfamethoxazole group, $\mathrm{p}=0.59$ ), norfloxacin was considered to be better tolerated than trimethoprimsulfamethoxazole. Eight patients (20\%) stopped taking trimethoprim-sulfamethoxazole because of its side effects, with resolution following cessation. There were not a significant difference in mortality rate between the norfloxacin and the trimethoprim-sulfamethoxazole groups ( $27.5 \%$ versus $17.5 \%$, respectively, $\mathrm{p}=0.28$ ).

Alvarez et al. (16) compared the effectiveness of trimethoprim-sulfamethoxazole versus norfloxacin in the prophylaxis of SBP in cirrhotic patients at high risk (Table 3). Of the 57 patients included, 32 received norfloxacin $400 \mathrm{mg}$ daily and 25 received trimethoprimsulfamethoxazole 160/800 mg five days a week. A total of 23 infections were recorded, $13(40 \%)$ in the 
norfloxacin group and $10(40 \%)$ in the trimethoprimsulfamethoxazole group $(\mathrm{p}=1.00)$. Three patients $(9.4 \%)$ in the norfloxacin group and four patients $(16 \%)$ in the trimethoprim-sulfamethoxazole group developed SBP, with no statistically significant difference $(p=0.68)$. Extraperitoneal infections were diagnosed in 10 patients under prophylaxis with norfloxacin $(31.3 \%)$ and in six patients under trimethoprim-sulfamethoxazole (24\%), with no statistically significant difference $(\mathrm{p}=0.42)$. The development of quinolone-resistant bacteria (Enterococcus) was detected only in one case of urinary infection in a patient using norfloxacin. The side effects were restricted to the trimethoprim-sulfamethoxazole group, all of limited repercussion. The drug was discontinued in only one patient. The mortality rate was similar in the two groups: $21.9 \%$ in the norfloxacin group and $20.0 \%$ in the trimethoprim-sulfamethoxazole group $(p=1.00)$.

In a prospective, double-blind, randomized and controlled trial, Rolachon et al. (13) evaluated the long-term use of ciprofloxacin for the prevention of SBP (Table 3). Seven patients included in the study had a previous history of SBP. Patients were assigned into two groups: group $1(\mathrm{n}=28)$, treated with one tablet of $750 \mathrm{mg}$ of ciprofloxacin each week for six months, and group 2 $(n=32)$, the placebo group. A statistically significant decrease in the incidence of SBP was observed in the treated group $(3.6 \%)$ as compared with the placebo group $(22 \%)(p<0.05)$. No significant difference was found between the patients of the treated group and those of the placebo group concerning the incidence of extraperitoneal infections ( $11 \%$ versus $12.5 \%)$. Tolerance of treatment was excellent because no adverse events occurred in the treated group. The overall mortality rate was $16.6 \%$, with no significant difference between groups. No deaths secondary to SBP were seen in either the treated or placebo group, and any death could be attributed to the treatment. Bacteriological study showed no acquired resistance to ciprofloxacin after six months of treatment.

Singh et al. (18) assessed the efficacy and safety of trimethoprim-sulfamethoxazole for the prevention of SBP in 60 patients with documented cirrhosis and ascites (Table 3 ). The patients were randomly assigned to receive trimethoprim-sulfamethoxazole five times a week $(n=30)$ or no prophylaxis $(n=30)$. Infectious complications developed in nine patients $(30 \%)$ not receiving prophylaxis and in one patient $(3 \%)$ receiving trimethoprim-sulfamethoxazole $\quad(p=0.012)$. SBP or spontaneous bacteremia developed in eight patients $(27 \%)$ receiving no prophylaxis and in one patient $(3 \%)$ receiving trimethoprim-sulfamethoxazole $(p=0.025)$. None of the patients developed adverse effects. No hematologic toxicity could be attributed to trimethoprimsulfamethoxazole. The overall mortality rate was lower in patients receiving trimethoprim-sulfamethoxazole (7\% compared with $21 \%$ ), although this was not statistically significant. No deaths, however, could be attributed directly to infection in either group.
In a prospective, randomized and controlled study, Soriano et al. (19) assessed the use of norfloxacin in the prevention of SBP and other infections in hospitalized cirrhotic patients (Table 3 ). Four patients had a history of previous SBP. Sixty-three patients were included in the study and randomly allocated into two groups: group $1(\mathrm{n}=32)$ received norfloxacin $400 \mathrm{mg} /$ day and group 2 $(n=31)$, controls, did not. The overall rate of infection was $3.1 \%$ from group 1 and $41.9 \%$ from group $2(\mathrm{p}<0.005)$. There were seven cases of SBP in seven patients from group $2(22.5 \%)$ and none in group $1(\mathrm{p}<0.05)$. Extraperitoneal infections were also less frequent in group $1(3.1 \%)$ than in group $2(22.5 \%)$, but not significantly so $(\mathrm{p}=0.052)$. One patient taking norfloxacin developed a skin rash; another developed fever with negative cultures that resolved when norfloxacin treatment was stopped. There were two deaths $(6.2 \%)$ in group 1 and five $(16.1 \%)$ in group 2 , but this difference did not reach statistical significance. Infection was the direct cause of death in four patients from group 2, whereas no deaths in group 1 were attributable to this cause.

\section{Discussion}

The present systematic review was performed to assess clinical efficacy of primary and secondary prophylaxis of SBP and to evaluate what is the most efficacious and safest antibiotic prophylactic strategy.

Regarding primary prophylaxis, two studies $(11,12)$ demonstrated that daily norfloxacin was effective in the prevention of infections, including SBP, in cirrhotic patients. One study (17) showed that norfloxacin was more efficacious in preventing the first SBP episode in cirrhotic patients when it was given continuously instead of only during hospitalization. Yim et al. (6) demonstrated that weekly ciprofloxacin was not inferior to daily norfloxacin, and Lontos et al. (5) showed that trimethoprim-sulfamethoxazole and norfloxacin had similar efficacy for primary prophylaxis of SBP. Another possible prophylactic strategy for primary prevention of SBP is the alternating use of rifaximin and norfloxacin, which demonstrated a higher prophylactic rate when compared with norfloxacin, the most widely used antibiotic in this setting (10).

Looking at secondary prophylaxis, one study (14) showed that norfloxacin reduced the probability of SBP recurrence. When daily norfloxacin was compared with weekly rufloxacin (9), the 3-month probability of SBP recurrence was significantly lower with norfloxacin, however the 1-year probability of SBP recurrence was similar between these two prophylactic strategies. Lontos et al. (5) showed that norfloxacin and trimethoprimsulfamethoxazole had similar efficacy for secondary prophylaxis of SBP. Two recent studies $(8,15)$ showed that rifaximin was more effective than norfloxacin in the secondary prophylaxis of SBP.

Based on the results of three studies $(13,18,19)$, either daily norfloxacin, weekly ciprofloxacin or trimethoprim- 
sulfamethoxazole five days a week were effective as prophylactic antibiotics in the prevention of SBP in patients with cirrhosis. Two studies $(5,16)$ showed that daily norfloxacin and trimethoprim-sulfamethoxazole (daily or five days a week) had similar efficacy for infection prophylaxis. One study (6) showed that weekly ciprofloxacin was not inferior to daily norfloxacin, which is a current standard therapy.

The majority of trials evaluating norfloxacin reported none or only minor side effects of norfloxacin, which did not require the withdrawal from the study $(10,11,14,17)$. Norfloxacin was stopped because of side effects (nausea, hypersomnia, severe diarrhea, granulocytopenia, urticaria, skin rash and fever) in seven patients from three trials $(9,12,19)$, with all side effects disappeared on discontinuation of the drug. Adverse events like nausea, vomiting and headache, occurred in three patients taking rufloxacin, however all of them resolved with drug cessation (9). No adverse events were reported with weekly ciprofloxacin (13). No serious adverse events occurred with patients taking rifaximin $(8,15)$, with a significant decrease in side effects with rifaximin versus norfloxacin (8). Trimethoprim-sulfamethoxazole was associated with an increased risk of developing an adverse event compared to norfloxacin $(5,16)$. In one study (5) eight patients stopped trimethoprimsulfamethoxazole due to gastrointestinal, renal and skin related side effects, although all adverse events resolved with drug discontinuation. In contrast, Singh et al. (18) did not report any adverse events related to trimethoprimsulfamethoxazole.

In what concern to mortality, only one study (11) demonstrated a benefit in mortality rate with antibiotic prophylaxis with norfloxacin over placebo. Elfert et al. (8) showed that the mortality rate was significantly decreased in the rifaximin group (13.74\%) compared with the norfloxacin group $(24.43 \%) \quad(p=0.044)$. In the remaining studies, there was no between-group difference in overall death rate or cause of death $(5,10,16,17)$.

Resistance to quinolones was observed in six studies in which patients were treated with these antibiotics $(5,6,8,9,11,17)$.

In summary, continuous long-term selective intestinal decontamination with norfloxacin is the most widely used prophylactic strategy in SBP, recommended by international guidelines (4). This descriptive analysis showed that once weekly administration of ciprofloxacin was not inferior to once daily norfloxacin in long-term prevention of SBP, with good tolerance and no induced resistance. Based on these data and considering cost effectiveness, availability, and drug compliance, once weekly ciprofloxacin could be a good alternative to daily norfloxacin $(6,13)$. This systematic review also showed that trimethoprim-sulfamethoxazole could be a viable alternative to norfloxacin with the advantage of being cheaper, which could improve treatment adherence. However, trimethoprim-sulfamethoxazole was associated with an increased risk of developing an adverse event

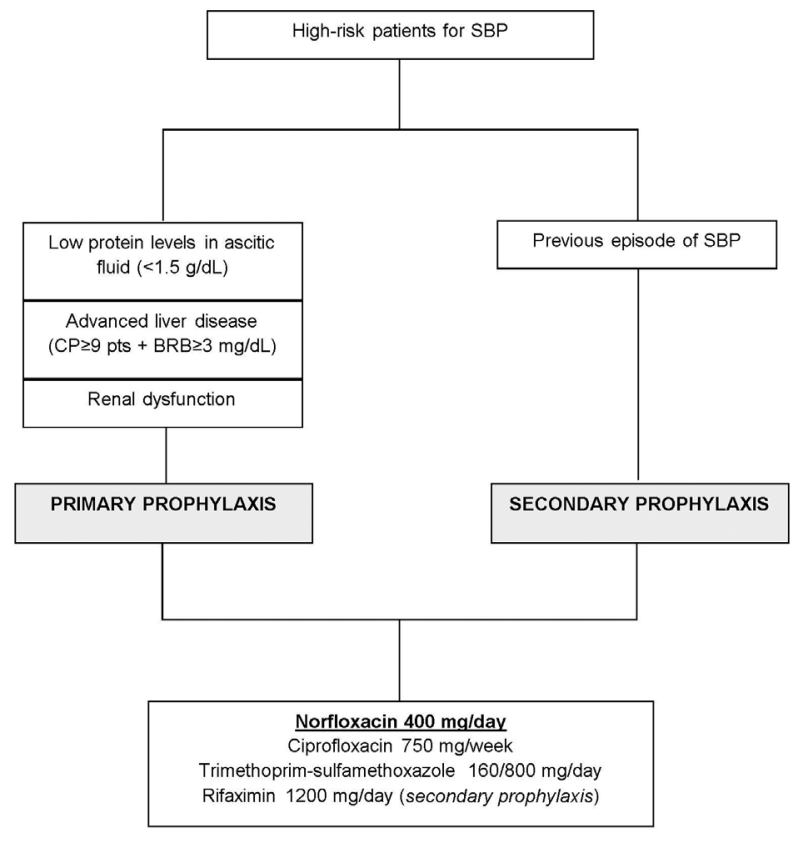

Figure 2. - Algorithm for antibiotic prophylaxis of spontaneous bacterial peritonitis. SBP, spontaneous bacterial peritonitis; CP, Child-Pugh score; pts, points; BRB, serum bilirubin level.

when compared to norfloxacin $(5,16)$. Another attractive approach for prophylaxis of SBP evaluated in this review is intestinal decontamination with rifaximin, which was more effective than norfloxacin in the secondary prevention of SBP, with a significant decrease in adverse events and mortality rate $(8,15)$. Although data on the impact of prophylactic antibiotics on survival is scarce, Fernández et al. (11) highlighted that antibiotic primary prophylaxis has a significant effect on the natural history of patients with advanced cirrhosis, with a significant increase in the 3-month and 1-year probability of survival ( $>30 \%$ and $>10 \%$, respectively).

Based on the results of this systematic review, a suggested algorithm for antibiotic prophylaxis of spontaneous bacterial peritonitis is shown in Fig. 2.

Several challenges and limitations were found in this review. Firstly, there was a great heterogeneity regarding sample size and participants baseline characteristics. Patients with variable risk factors for SBP were included in the trials, making it difficult to establish which group of patients derived the most benefit from prophylactic antibiotic use. There also was a relevant heterogeneity concerning follow-up periods. Secondly, the current definition of SBP, internationally accepted, is based on neutrophil count in ascitic fluid of $>250 / \mathrm{mm}^{3}$ (4). Some of the trials included in this systematic review used variations of this definition, which can represent another important limitation. Additionally, RCTs incorporated in the review varied in their quality, this is, in risk of bias, mainly because experimental designs and methods for allocation concealment and blinding of personnel and 
outcomes were quite heterogeneous among studies. It is important to note the introduction of language bias in this review because only studies written in English were included.

Considering the mentioned limitations, further studies should concentrate on the following points. It is necessary to establish risk factors for inclusion in primary and secondary SBP prophylaxis trials and standardize exclusion criteria in these protocols. It is important to establish appropriate time-points to measure and analyze the outcomes. It is also essential to design trials with longer follow-up periods to establish the optimal duration of antibiotic prophylaxis. The new protocols should always separate primary from secondary prophylaxis, or at least make a subgroup analysis for each type of prophylaxis. Further head-to-head trials are necessary to compare different regimens in the antibiotic prophylaxis of SBP. Additional randomized trials are necessary to investigate if the rise in resistant bacteria counterbalances the benefit of primary prophylaxis in these patients. Finally, since novel antibiotic classes are lacking, new prophylactic strategies which do not induce bacterial resistance should be pursued. Recent data $(20,21)$ suggest that long-term albumin administration in patients with decompensated cirrhosis improves survival and reduces the incidence of severe life-threatening complications including SBP and non-SBP bacterial infections, renal failure, hyponatremia and hepatic encephalopathy. Besides its colloid-osmotic effect, the albumin molecule has pleiotropic, non-oncotic properties targeted to systemic inflammation, oxidative stress, immune dysfunction and circulatory dysfunction, making it a disease-modifying treatment in patients with decompensated cirrhosis.

\section{Conclusion}

Based on currently available data, we conclude that despite norfloxacin is the most widely investigated prophylactic strategy in spontaneous bacterial peritonitis, there are other equally effective and safe options for SBP prophylaxis such as ciprofloxacin, trimethoprimsulfamethoxazole and more recently rifaximin. However, due to lack of large head-to-head trials, we cannot be certain about what is the most efficacious and safest antibiotic prophylactic strategy. Further head-to-head trials are urgent in order to compare different antibiotic regimens in the prophylactic prevention of SBP.

\section{Statement of Ethics}

The authors have no ethical conflicts to disclose.

\section{Disclosure Statement}

The authors have no conflicts of interest to declare.

\section{Funding Sources}

This work was not funded.

\section{References}

1. MARCIANO S., DÍAZ J.M., DIRCHWOLF M., GADANO A. Spontaneous bacterial peritonitis in patients with cirrhosis : incidence, outcomes, and treatment strategies. Hepat. Med., 2019, 11: 13-22.

2. LUTZ P., NISCHALKE H.D., STRASSBURG C.P., SPENGLER U. Spontaneous bacterial peritonitis: the clinical challenge of a leaky gut and a cirrhotic liver. World J. Hepatol., 2015, 7(3) : 304-314.

3. AL-GHAMDI H., AL-HARBI N., MOKHTAR H., DAFFALLAH M., MEMON Y., ALJUMAH A.A., et al. Changes in the patterns and microbiology of spontaneous bacterial peritonitis: analysis of 200 cirrhotic patients. Acta Gastroenterol. Belg., 2019, 82(2) : 261-266.

4. THE EUROPEAN ASSOCIATION FOR THE STUDY OF THE LIVER. EASL Clinical Practice Guidelines for the management of patients with decompensated cirrhosis. J. Hepatol., 2018, 69(2) : 406-460.

5. LONTOS S., SHELTON E., ANGUS P.W., VAUGHAN R., ROBERTS S.K., GORDON A., et al. A randomized controlled study of trimethoprimsulfamethoxazole versus norfloxacin for the prevention of infection in cirrhotic patients. J. Dig. Dis., 2014, 15(5) : 260-267.

6. YIM H.J., SUH S.J., JUNG Y.K., YIM S.Y., SEO Y.S., LEE Y.R., et al. Daily norfloxacin vs. Weekly ciprofloxacin to prevent spontaneous bacterial peritonitis: a randomized controlled trial. Am. J. Gastroenterol., 2018, 113(8) : 1167-1176.

7. CENTRE FOR REVIEWS AND DISSEMINATION. Systematic reviews: CRD's guidance for undertaking reviews in health care. 3rd ed. York : CRD, 2009.

8. ELFERT A., ABO ALI L., SOLIMAN S., IBRAHIM S., ABD-ELSALAM S. Randomized-controlled trial of rifaximin versus norfloxacin for secondary prophylaxis of spontaneous bacterial peritonitis. Eur. J. Gastroenterol. Hepatol., 2016, 28(12) : 1450-1454.

9. BAUER T.M., FOLLO A., NAVASA M., VILA J., PLANAS R., CLEMENTE G., et al. Daily norfloxacin is more effective than weekly rufloxacin in prevention of spontaneous bacterial peritonitis recurrence. Dig. Dis. Sci., 2002, 47(6) : 1356-1361.

10. ASSEM M., ELSABAAWY M., ABDELRASHED M., ElEMAM S., KHODEER S., HAMED W., et al. Efficacy and safety of alternating norfloxacin and rifaximin as primary prophylaxis for spontaneous bacterial peritonitis in cirrhotic ascites: a prospective randomized open-label comparative multicenter study. Hepatol. Int., 2016, 10(2) : 377-385.

11. FERNÁNDEZ J., NAVASA M., PLANAS R., MONTOLIU S., MONFORT D., SORIANO G., et al. Primary prophylaxis of spontaneous bacterial peritonitis delays hepatorenal syndrome and improves survival in cirrhosis. Gastroenterology, 2007, 133(3) : 818-824.

12. GRANGÉ J.D., ROULOT D., PELlETIER G., PARIENTE E.A., DENIS J., INK O., et al. Norfloxacin primary prophylaxis of bacterial infections in cirrhotic patients with ascites: a double-blind randomized trial. J. Hepatol., 1998, 29(3) : 430-436.

13. ROLACHON A., CORDIER L., BACQ Y., NOUSBAUM J.B., FRANZA A., PARIS J.C., et al. Ciprofloxacin and long-term prevention of spontaneous bacterial peritonitis : results of a prospective controlled trial. Hepatology, 1995, 22(4) : 1171-1174

14. GINÉS P., RIMOLA A., PLANAS R., VARGAS V., MARCO F., ALMELA M., et al. Norfloxacin prevents spontaneous bacterial peritonitis recurrence in cirrhosis: results of a double-blind, placebo-controlled trial. Hepatology, 1990, 12(4) : 716-724

15. MOSTAFA T., BADRA G., ABDALLAH M. The efficacy and the immunomodulatory effect of rifaximin in prophylaxis of spontaneous bacterial peritonitis in cirrhotic Egyptian patients. Turk J. Gastroenterol., 2015, 26(2) : 163-169.

16. ALVAREZ R.F., MATTOS A.A., CORRÊA E.B., COTRIM H.P., NASCIMENTO T.V. Trimethoprim-sulfamethoxazole versus norfloxacin in the prophylaxis of spontaneous bacterial peritonitis in cirrhosis. Arq. Gastroenterol., 2005, 42(4) : 256-262.

17. NOVELLA M., SOLÀ R., SORIANO G., ANDREU M., GANA J., ORTIZ $\mathrm{J}$., et al. Continuous versus inpatient prophylaxis of the first episode of spontaneous bacterial peritonitis with norfloxacin. Hepatology, 1997, 25(3) : $532-536$.

18. SINGH N., GAYOWSKI T., YU V.L., WAGENER M.M. Trimethoprimsulfamethoxazole for the prevention of spontaneous bacterial peritonitis in cirrhosis: a randomized trial. Ann. Intern. Med., 1995, 122(8) : 595-598.

19. SORIANO G., GUARNER C., TEIXIDÓ M., SUCH J., BARRIOS J., ENRÍQUEZ J., et al. Selective intestinal decontamination prevents spontaneous bacterial peritonitis. Gastroenterology, 1991, 100(2) : 477-481.

20. ZACCHERINI G., BERNARDI M. The role and indications of albumin in advanced liver disease. Acta Gastroenterol. Belg., 2019, 82(2) : 301-308.

21. CARACENI P., RIGGIO O., ANGELI P., ALESSANDRIA C., NERI S., FOSCHI F.G., et al. Long-term albumin administration in decompensated cirrhosis (ANSWER): an open-label randomised trial. Lancet, 2018, 391 : 2417-2429. 